\title{
INTERCULTURAL COMMUNICATION AT HIGHER EDUCATION CONTEXT: PORTRAITS AND PRACTICES
}

\author{
Muh. Basri Wello \\ University of Indonesia Timur \\ Email:Mbasriwello6@gmail.com \\ Sahril Nur \\ State University of Makassar \\ Email:Sahril@gmail.com \\ Astuti Azis \\ Department of Education, Gowa Regency \\ Email: tuty_asiz@yahoo.com
}

\begin{abstract}
Intercultural communication focuses on the importance of understanding other's language and cultural background in order to create appropriate and effective communication. This article reviews several studies on intercultural competence from five different countries. The objective of this review is to present research from different context, models of intercultural communication developed in those settings and possible adaptive models to develop in Indonesian higher educational settings. Data were obtained from a careful review of international articles on the study of intercultural communication using inclusion and exclusion criteria. Result of the review reveals that culture is still the biggest issue that could block effective and relevant communication. For that reason, intercultural communication, (IC) positively contribute to the development of cultural sensitivity and is open for adaptation to work in different context. Suggestions on effective model of intercultural education at university level and applicable sample of collegial relationship among academics are also provided.
\end{abstract}

Keywords: Intercultural Communication, Higher Education, Portraits and Practices

\section{INTRODUCTION}

Intercultural competence is usually introduced in different terms, some people refers to it as cross-cultural adaptation, intercultural sensitivity, multicultural competence, global competence, international competence, global literacy, cultural competence, intercomprehension and many more. In this review the term intercultural communication, intercultural competence and intercomprehension are used interchangeably.

In a study of intercultural approach in education, Davies and Rey (1996) denoted that intercultural refers to 'inter' and 'culture'; inter means interaction, exchange and open.
Culture on the other hand signifies life style, representative symbol used by people either individually or through community in building relationship with others in their effort to understand the world; to comprehend interaction within intra and inter cultures. In that interaction, space and time should always be considered. In other words, 'intercultural' is a dynamic process which consist of real interconnected interaction. Intercultural should involve positive interaction among its components and actors in the society and at the same time indicate representation and action perspective. In short, intercultural is cultural intercation which will result in 
positive relationship among actors who take part in the process.

Bowden and Marton (1998) distinguish competence into two. The first one refers to a series of freedom, observable attitude (in the work place) and the second one refers to ability to see and cope with new situation with effective strategy including ability to adapt with discipline and professionalism. These authors argue that discipline and professionalism are two components that should be integrated. They also denotes that these elements are crucially implemented with practical approach either in work place and in university because students needs various experience and diversity to enable them facing unpredicted future. Other important point is that competence is believed to depend on relationship and situation on how community count others (Lustig \& Koester, 2003). Thus IC is a strong and durable characteristics that every students need to master. IC would enable students to build good relationship with others, play their roles well as professionals and able to overcome any problems related to inter- cultural communications.

Intercultural competence (IC) is inseparable with communication competence and intercultural communication (Deardorff, 2004). According to Spitzberg and Cupach (1984) communication competence consists of several components like social competence and inter personal competence. Both components are focused on result, linguistic competence and communication competence. This means that intercultural comprehension concern with understanding and accepting others' diversity and differences either individual or group in order to build democratic society. This also indicates that multicultural education should actually addresses to all society that they can live in harmony as the precondition of unity in a society (Melkote \& Steeves, 2015; Rao \& Thombre, 2015).
To this end, intercultural competence (IC) is the big theme with several sub themes including skills, attitude, and knowledge. (Snow, 2015). In the teaching of intercultural competence, the main goal of teaching the course is to develop and improve intercultural communication skills that could facilitate students coping with various intercultural problems in the future regardless differences in cultural background Snow (2015). In line with the idea, Tibury and Henderson (2003) contend that intercultural education consists of equity, participation, peace, appreciation, reconsiliation and cooperation. Education that focuses on intercultural comprehension offers opportunity to exchange values, skills/knowledge, art/ science and understanding wider diverse culture, religion and values. This understanding signifies that in the context of multicultural education human right is the most important thing that will result in appreciating others. This concept in the end will create positive attitude and behavior like appreciation of others' feeling, empathy and brotherhood that could broaden perspective and knowledge and prevent inferior attitude to other group. In practice, intercultural education should based on several criteria: (1) focus on equity between individual and group; (2) be able to accept cultural and language differences and diversity as a source of learning; (3) avoid ethnocentrism; and (4) aim to achieve the same opportunity and oppose any kind of discrimination and racism (Fossard \& Bailey, 2016).

In the last decades, IC becomes more popular and was considered to be an independent subject. Some universities introduce the program in a form of workshop, some other run exchange program, few invite guest speakers from different culture in class and many more. It appears that IC now becomes a demand and its objective is broaden. The program has transformed into an 
obligatory subject for having relevant and effective communication. As stated before, the course aims to prepare students to understand others, their culture and cope with any intercultural incidents in the future. The last point is the main objective of this research, particularly prepare business English students with intercultural- related information and skills that could assist them overcome conflict and potential shock later in their future.

In an effort to meet this objective, we try to present evidence based practice in the area of intercultural competence. In this article, I provide a review of studies on intercultural competence from five different countries. The objective of this review is to presents research from different context, models of intercultural communication developed in those settings and possible adaptive models to develop the lesson in higher education settings.

This review is divided into five sections. The first one explains the study followed with description of method used for the study. The third section provides overview of the selected articles. Section four discusses and critiques the articles and closes with summary of the review.

\section{METHOD}

I searched the internet search engine, journal finder, and google scholar in the areas of intercultur- al communication, intercultural competence, intercomprehension, and effective learning. The various literature searches resulted in 16 studies which led me to apply the exclusion and inclusion criteria.

To be included in this review, the article had to be a research study that examined intercultural communication or intercultural competence. Criteria for inclusion cover studies conducted at higher education settings, accomplished in different contexts to present different beliefs and related factors, carried out in language learning or communication context and published within 2009 to 2015.
Studies that is written as a book review (Snow, 2015; Weng, 2015); conducted at other institution such as mental health service (Bourjolly, Sands, Solomon, Stanhope, Pernell-Arnold, \& Finley 2005); or community base ( Barker, 2015), employed teachers rather than students (Ngai \& Janusch, 2015); implemented for real situation like tourism (Kirillova, Lehlu, Ces, 2015) \& for workers (Martin \& Nakayama, 2015); Study that investigating survey on willingness to engage in intercultural interactions (Kassing, 2009) and studies conducted before 2009 ( Wasonga $\&$ Piveral, 2004) were not included.

\section{OVERVIEW OF ARTICLES}

From the list of potential studies, several studies were excluded leaving 5 studies investigating university settings' intercultural communication/competence for summary and analysis. Before presenting the summary of the reviewed articles it is advantegous to highlight the IC component that considered to be studied. Referrring to the INCA or intercultural assessment, several points of investagion includes general profile, tolerance of ambiguity, behavioural flexibility, communicative awareness, knowledge discovery, respect for otherness and empathy. The following is the summary of the topic, participants, methods, findings, and recommendations for each of the five included studies.

Pinhoa (2015) conducted a class action research involving four female student teachers aged 21-22 who were taking a degree in the teaching of Portuguese (mother tongue) and English (as a foreign language) at the University of Aveiro, Portugal. She collected data through participants' learning journals, reflective notebooks and transcriptions of the interviews carried out with the studentteachers before and after the implementation of The Education Path to Intercomprehension (EPI). Using both hermeneutic perspective and content analysis for data anysis, the 
researcher reported the following findings. The path enabled students-teachers to critically relect on their life episodes and experience as language teachers which contribute to the development of their cultural sensitivity and use the result of reflections as an adaptation strategy in their teaching context. The program also allow participants to discuss topics to expand their thinking about world of languages, cultures and communication. In addition, they also inevitably able to enrich the notion of IC by considering it in the light of the role as language teachers and their professional identity. This means that the implementation of EPI have developed student-teacher critical cultural awareness, interpretation and relating skills and attitudes. The study recommend that IC is an effective pathway for developing teachers' intercultural sensitivity and professional identity in three interconnected dimensions: political, social \& critical (theachers is seen as social actors); didiactic or curricular interventions (teachers is seen as curriculum manager and decision maker); \& personal \& relational dimension (role of teacher as linguistic, communicative and rofessional biography and identity.

In the second study, Fall, Kelly, MacDonald, Primm, and Holmes (2013) examine individuals' apprehension prompted by intercultural communication and the relationship it may have with their emotional intelligence. Involving 425 undergraduate students studying public speaking at Southeastern University. Respondents came from various nationalities including African, Latino, Asian, and Native American. They use two instruments for data collection. The Intercultural Communication Apprehension (ICA) was measured using The Neuliep and McCroskey's (1997) Personal Report which consisted of 14 Likert-type items and participants' emotional intelligent was measured through the Trait Emotional Intelligence Questionnaire-Short Form
(Petrides \& Furnham, 2006) which consisted of 30 Likert-type items both with 7-point response scales ranging from agree strongly to disagree strongly. The results from this study confirmed a negative relationship between emotional intelligence and inter- cultural communication apprehension. The implication of this finding is that individuals with higher emotional intelligence may be able to mitigate apprehension caused by intercultural communication. Meaning that methods to bolster students' EI should be considered to impact their ICA. This study also reveal that only three of the four subdimensions of EI predicted ICA they are self-control, emotionality, and sociability were statistically significant predictors while well-being was not. These findings, which support that EI may mitigate ICA, lead to a simple academic outcome that is higher education business faculty should strongly consider integrating EI into their business and professional communication curriculum. Claim that more emotionally intelligent students are more effective and culturally competent young professionals is not novel. Writers of the study recommend that University should consider the integration of EI in the effort to prepare students for the globalized business world. This includes conducting lectures and workshops to teach students about emotional intelligence, personal competencies, and social competencies. Among personal competencies suggested covering self awareness, self-regulation, and selfmotivation while skills for social competencies includes social awareness and social skills; and their relevance to the workforce.

The third study was conducted in Indonesia. Gandana and Parr (2013) studying professional identity, curriculum and teaching intercultural communication by examining values, beliefs and understandings that are perceived to influence teacher's identity and work and how these elements mediate and 
shape teachers' discourses and classroom practices. Employing qualitative case study involving one female teacher teaches Intercultural Communication in one university in West Java, the researchers reported data mainly from interview although other instruments such as classroom observation notes and curriculum and policy documents were also used. Data were collected from September to December 2010. The study founds that the participant who gained her master degree abroad tried to implement egalitarian concept in teaching like interrupting during lecturer. However she was also conflicted with culture and feeling that she need to be respected as teacher for her professional identity. In short, she still negotiate about her teaching identity in mind while trying to contruct affirmed relatonship with students. Further finding reveals that although the participants experience inconsistencies and found irrelevancies between curriculum content and the essense of inter- cultural communication, she could not do much on that. This phenomenonn reflect tension between personal beliefs and institutional demand. Moreover, The participants reported that there is more hierarchial relationship rather than collegial between coteacher and primary teacher. Interestingly, this teacher appered to be Influenced by her experience living abroad; she realizes that there is a world Englises where everybody could speak with own style without needing to to be native like. She particularly insist this point to her students in order to encourage them to speak up. This study suggest that, participant's autonomy and agency as a teacher were challenged by a number of contextual factors, such as the hierarchical institutional culture, language, culture and curriculum demands prescribed by the faculty as well as limited resources. This led to occasional tensions between her stated beliefs and her instructional practices. As intercultural pedagogy focused more on how we teach rather than what we teach, the incorporation of interculturalism in teaching should signify more than just the introduction of new courses. This means that teachers need to be given space to innovate and to be curriculum developers rather than being merely curriculum imple- menters. They also need to be given opportunities to be involved in ongoing conversation, collaboration and co-construction of knowledge with other academics.

The fourth study investigates intercultural sensitivity of student teachers in Hong Kong, Shanghai \& Singapore, Yuen and Grossman (2009) interested to figure out students teachers levels of intercultural sensitivity and the implications of their levels for teacher education. These reasearcher previously assumed that the three cities failed to translate their need to be equipped with global awareness and skills into adequate school ethos, and internation- al/intercultural awareness of teachers which lead to their failure to achieve their goal to be commensurated with world city. Working on the issue, the researchers work with 317 participants in total and employ the Intercultural Development Inventory (IDI) questionnaire developed by Hammer and Bennett (2001) which consist of 50 item with 5 point likert' scale as the instrument for collecting data. The finding shows that $86.36 \%$ participants pere- cived their own cultural view as universal, meaning that they fond of their own culture and tended to isolate physcohogical/phyisical differences. Interestingly, it appears that the level of intercultural sensitivity of the three cities are different where Shanghai was the highest followed by Singapore. This indicates that Shanghai sample have a better estimation of in- tercultural competence than their two counterparts. The demographic information also illustrates that the majority participants' do not have adequate experiences in dealing with cultural identity problems. However, the 
more teaching experience they have the higher developmental score they get. This means that teaching experience contributes to the development of intercultural sensitivity. These findings indicate that preparing pre-service and in-service teachers with diversity and differences is a must. Among the reasons lies behind includes effective in- tercultural education for teacher should be provided in order that they could accept cultural differences of many apects of different ethnic groups and cope with that effectively and efficiently.

Hiller and Wozniak (2009) overviewed a program at uni level Viadrina, a university located at an international cross-border (German-Poland). The main aims of the program is to give students the possibility of experiencing, discovering and discussing the diversity of values and worldviews in special workshops introduces strategies to sensitize students on intercultural level within formalised structure of study program. The content and methods of the workshop is a combination of theoretical input and practical exercises concerning the topics of intercultural communication. Following the workshop, the writers also employ an open questionnaire asking participants feedback. Total of 122 questionnaire were analysed and resulted in six main themes includes: Respect for others, knowledge discovery, behavioural flexibility, tolerance for ambiguity, empathy, and behavioural flexibility, communicative awareness and respect for otherness. The authors framed these findings with the INCA model and concludes that all competences of the INCA are addressed in the workshops.

Among recommendations suggested from the study, the biggest one is the urge of introducing in- tercultural competence as acumpolsary program. These writers argue that making it an independent course is worth trying cause it offers a very good opportunity to get maximum interaction with intercultural topics. They insist that the strategy they introduced involves the acquisition of different skills which is necessary for students to cope in highly interconnected international contexts in which they already find themselves during their study or will probably find themselves in their later careers. In short, offering such program in higher education setting is both worth considered and essential.

\section{RESULT AND DISCUSSION}

This review focuses on universty students' experience on intercultural communication from several countries. All studies presented in this review were published between 2009 and 2015. Summary of these studies reveal that failure in understanding other's culture could result in severe problems that threat effective and relevant communication. All studies agree that intercultural compe- tence/commnication is the key to harmony relationship and successful interaction. Lesson from these studies suggest that IC is a mandatory subject to preapare students live in global village. These studies suggest model of effective intercultural education including running a workshop that offers students opportunity to perform role play related to the introduced theme.

The studies in this review involved 869 people in total. Participants were university students (student teacher) and mostly study at last semester. The biggest study has 425 participants, two others made up from 317 and 122 respondents, these three studies adopted quantitative paradigm and two others were qualitative employing class action research and case study with four and one participants respectively. The first three studies use questionnaires as the appropriate data source. This is relevant to McMillan and Schumacher (2010) claim that survey research accurately present information from a large number of people. In addition, the procedure also enables researchers to collect data about attitudes, beliefs, values, behaviours, 
opinions, characteristics and other types of information of the population (Creswell, 2005; MacMillan and Schumacher, 2010). In other words questionnaire reflects the appropriate choice in investigating students teacher understanding of in- tercultural communication. However, it should be considered a procedure preceding questionnaire that is a pilot test. This procedure gives the researcher opportunity to revise the instrument and make it more understandable, clearer and not ambiguous (Creswell, 2005). The fact that only two studies followed the procedure should suggest reflection for further research. In addition, the small scale studies in Portugal and Indonesia also reflect the right option of using interviews to collect data for measuring students' attitude. However, it might be insufficient to portray how the treatment or the implementation of intercultural education. The researchers might consider the use of observation because it provides 'the opportunity to record information as it occurs in a setting' (Creswell, 2005, p. 211). Moreover, observation is needed to ensure that participants' statements match with their action (Johnson and Christensen, 2008). Thus more qualitative studies are needed for further research in the field as well as the use of observation and document analysis to support the interpretation of the result of the study.

The identification of themes and methodological issues in the studies of this topic suggest further investigation in Indonesia. More practical example of intercultural incidents is worth considered and should open for adaptation in other context. This is necessary to organise more equipped students facing the real world of intercomprehension in the future.

In terms of educational implication, this review suggests the importance of IC in preparing students for future career. It also informs teachers to work collegial with other academics in preparing more effective model and plan of IC. These teachers shoul also be given autonomy and space to develop the lesson plan, adjust them with their own condition and setting and develop a new applicable model to apply in the context.We would appreciate it if you make use of the enclosed Endnotes stylefile (Harvard.ens).

\section{CONCLUSION}

This literature review presents intercultural competence/communication from different contexts, how they subject developed in ecah setting and model of effective strategy to adapt and adopt. It found that all studies recommend IC to be an independent subject. However each setting demonstrtae different strategy indicating an open adaptation from other context such as Indonesia.

Western settings represented by Potugal, Germany and USA recommend that IC is the right strategy to participate in the global worls. Researchers from these settings also suggest that curriculum should carefully developed in order to meet students/people's need. On the other hand, Hong Kong, Shanghai, Singapore and Indonesia which represent eastern context, implies that they realize the importance of the course and plan to prepare it more solemn for welcoming the free market. In summation, these studies have ring the bell and call for thorough and intensive program to run in order to meet the main objective of teaching intercultural competence.

This simple review is definitely insufficient to generalize the issue of interculural comprehension which means that further and deeper exploration in the field is needed to address. Learning from the studies presented in the review, conducting similar research in the qualitative paradigm and using various data collection methods such as observation and document analysis seem to be useful to present more accurate data. 
Another notes from the review is how to interpret several approach introduced in the studies. Considering factors that influence the efficacy of the program, adaptation and further research in preparing relevant and suitable approach to implement in Indonesia is worth considered. Some initial ideas to bear includes reflecting on own culture, create activities that could result in acquisition of experience, and run discussion about communication style.

\section{REFERENCES}

Barker, G. G. (2016). Cross-cultural perspectives on intercultural communication competence. Journal of Intercultural Communication Research,45(1), 13-30. doi:10.1080/17475759.2015.1104376

Bourjolly, J. N., Sands, R. G., Solomon, P., Stanhope, V., Pernell-Arnold, A., \& Finley, L. (2005). The journey toward intercultural sensitivity. Journal of Ethnic and Cultural Diversity in Social Work, 14(3-4), 41-62. doi: 10.1300/J051v14n03_03

Bowden, J., \& Marton, F. (1998). The university of learning. London: Kogan Page.

Davies, I., \& Rey, M. (1996). Exploring intercultural approaches to education. European Journal of Intercultural studies, $7(2), \quad 16-23 . \quad$ doi: $10.1080 / 0952391960070203$

Deardorff, D.K. (2004). The Identification and assessment on intercultural competence as a student outcome of internalization at institutions of higher education in the United States Doctoral, North Carolina State University, Raleigh, North Carolina.

Fossard, E., \& Bailey, M. (2016). Communication for behavior change: Using entertainment- education for distance education. India: Sage Publishing.
Kirillova, K., Lehto, X., \& Cai, L. (2015). Volunteer tourism and intercultural sensitivity: The role of interaction with host communities. Journal of Travel \& Tourism Marketing. doi: 10.1080/10548408.2014.897300

Lamb, M., \& Wedell, M. (2013). Inspiring English teachers: A comparative study of learner perceptions of inspirational teaching. ELT Research Paper, 13(03), 125.

Martin, J. N., \& Nakayama, T. K. (2015). Reconsidering intercultural (communication) competence in the workplace: A dialectical approach. Language and Intercultural Communication, 15(1), 13-28. doi: 10.1080/14708477.2014.985303

Melkote, S., \& Steeves, H. (2015). Communication for development: Theory and practice for empowerment and social justice. India: Sage Publishing.

Ngai, P., \& Janusch, S. (2015). Intercultural communication training for English language teachers: A case study of an immersion program for South Korean Teachers. Journal of Intercultural Communication Research, 44(4), 345-368. doi: 10.1080/17475759.2015.1081853

Rao, R., \& Thombre, A. (2015). Intercultural communication: The Indian context. India: Sage Publishing.

Snow, D. (2015). English teaching, intercultural competence, and critical incident exercises. Language and Intercultural Communication, 15(2), 285299. doi: 10.1080/14708477.2014.980746

Sahril. (2016). Motivational strategies of Indonesian EFL lecturers: A case study of EFL teaching practices in a public university classroom setting. Doctoral, State University of Makassar, Makassar.

Spitzberg, B. H., \& Cupach, W. R. (1984). Interpersonal communication competence. London: Sage. 
Tibury, D., \& Henderson, K. (2003). Education for intercultural understanding in Australian schools: A review of its contribution to education for a sustainable future,. Australian Journal of Environmental Education, 18.

Wasonga, T. A., \& Piveral, J. A. (2004). Diversity and the modeling of multicultural principles of education in a teacher education program. Multicultural Perspectives, 6(3), 42-47. doi: $10.1207 / \mathrm{s} 15327892 \mathrm{mcp} 0603 \_9$

Weng, L. (2015). Intercultural communication for everyday life. Language and Intercultural Communication, 15(4), 622627. doi: $10.1080 / 14708477.2015 .1053177$

Duigu, Gaby. (2003). Essay Writing for English Test. Sydney: Academic English Press.

Gay, Lorrie R, Mills, Geoffrey E, \& Airasian,Peter W. 2011. Educational Research: Competencies for Analysis and Applications. $10^{\text {th }}$ Edition. California: Prentice Hall.

Goose, Allen. (2001). Eight Kinds of Writing: Lesson and Practice for Writing
Tests. Second Edition. Portland: Weston Walch Publisher.

Hayes, John. (2011). Kinds of Knowledge Telling: Modeling Early Write Development. Journal of Writing Research. Vol. 03, No. 2. pp. 366-384.

Langan, John. (2008). College Writing Skills. Sydney: McGraw-Hill Press.

Leitjen, Marielle, Et Al. (2011). Coordinating Sentence Composition With Error Correction: A Multilevel Analysis. Journal of Writing Research. Vol. 02 No. 03. Pp. 331-363

Piolat, Anni \& Frutttero, Laurant. (2011). Effects Of Memory Span on Cognitive Load and On Writing Strategies. Journal Of Writing Research. Vol. 03, No. 2. Pp. 366-384.

Sulistyo, Gunadi, H. (2008). English as A Measurement Standard in The National Examination: Some Grassroots' Voice. LINGUA: Journal Ilmu Bahasa dan Sastra. Vol. 3 No. 2.

Torrance, Mark. (2011). Learning to Write Effectively: Current Trend in European 